\title{
Long-term Safety of Sonidegib in Basal Cell Carcinomar 30-Month Results from the BOLT Trial
}

Ragini Kudchadkar, MD'; Anne Lynn S. Chang, MD²

'Associate Professor, Hematology and Medical Oncology, Emory University School of Medicine, Atlanta, GA, USA; 'Associate Professor, Dermatology, Stanford University School of Medicine, Redwood City, CA, USA.

\section{BACKGROUND}

Basal cell carcinoma $(\mathrm{BCC})$ is the most common
form of skin cancer'

More than 4 million cases are
United States (US) each year

The incidence and prevalence of $B C C$ is expected

to increase as the population ages

$\sim 95 \%$ of patients with BCC have mutations in the Pedgehog (HH) signaling pathway components

Sonidegib blocks the $\mathrm{HH}$ signaling pathway by selective inhibition of the SMO protein ${ }^{5}$ (Figure 1 )

Figure 1. Sonidegib Mechanism of Action

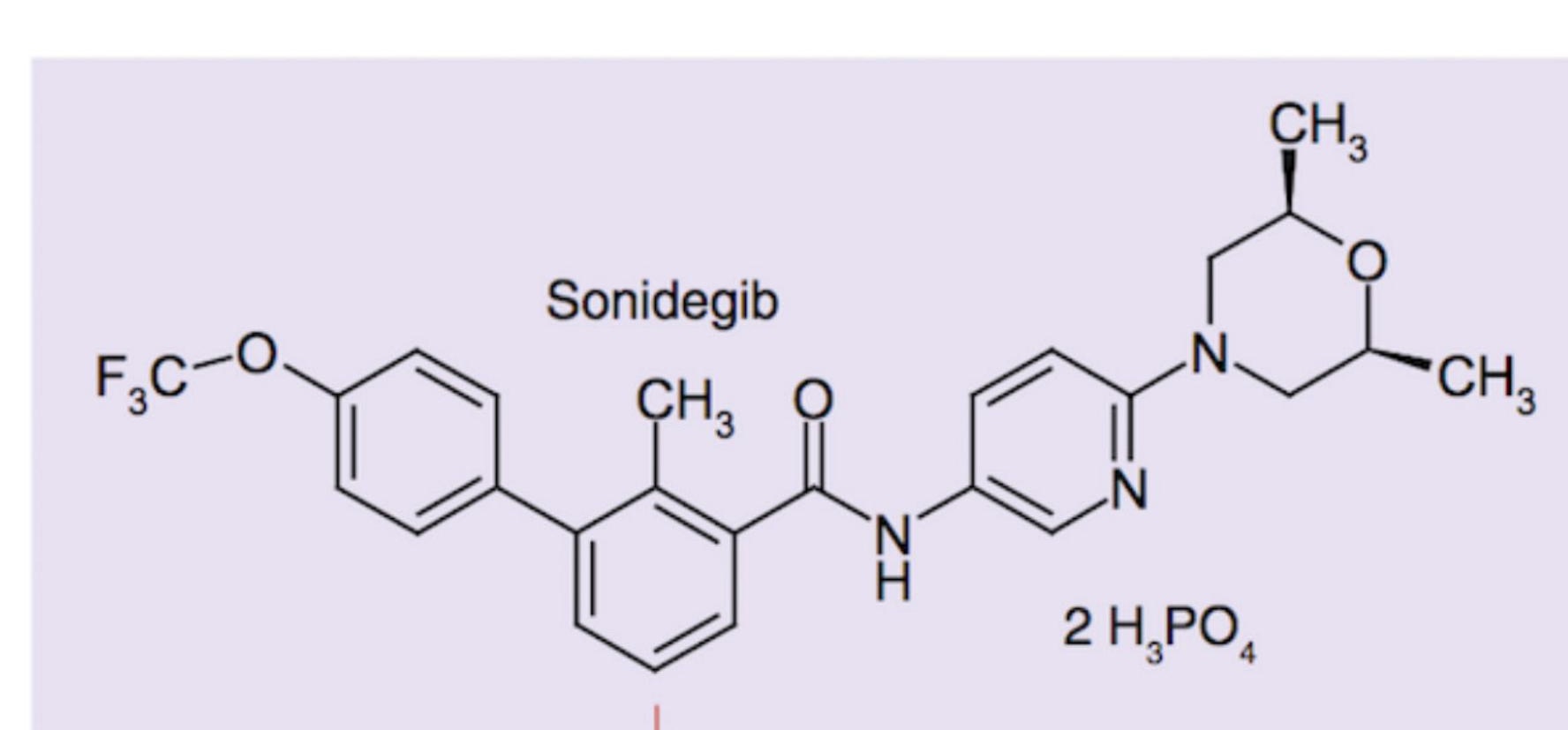

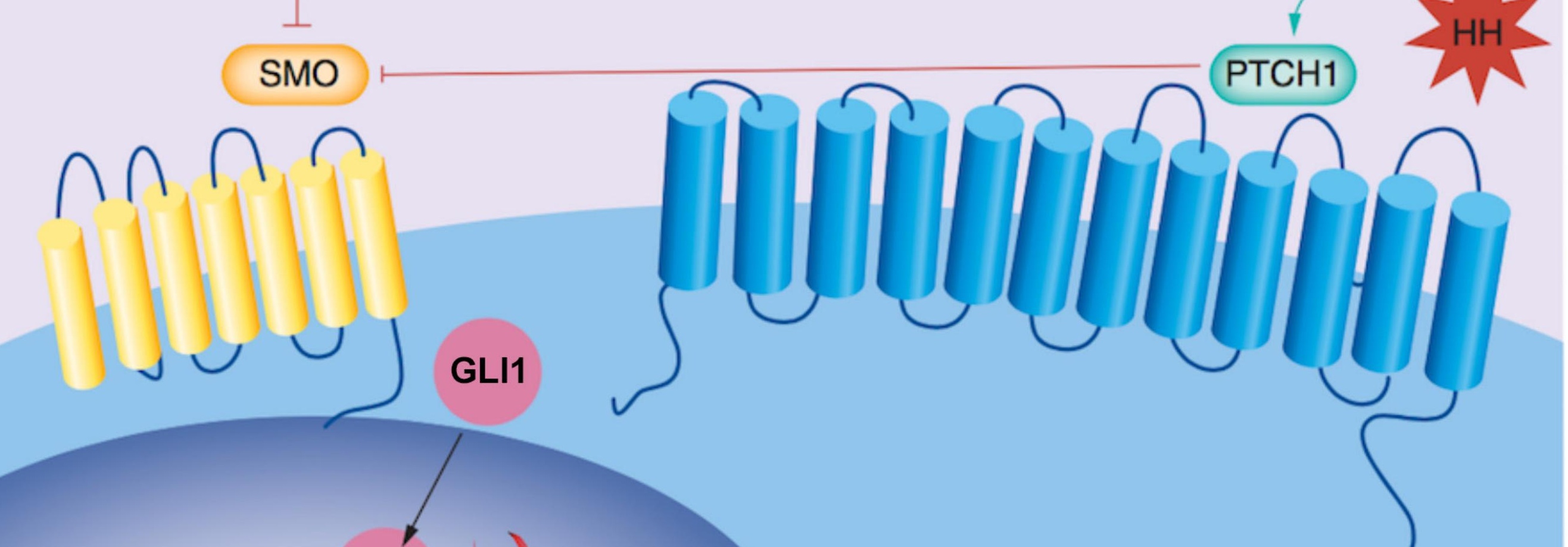

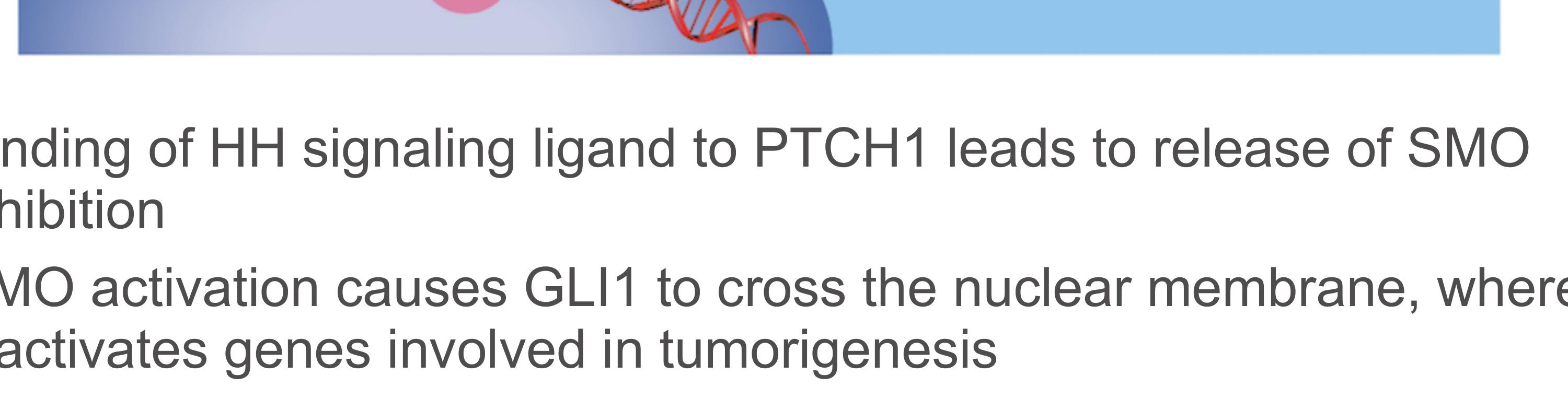

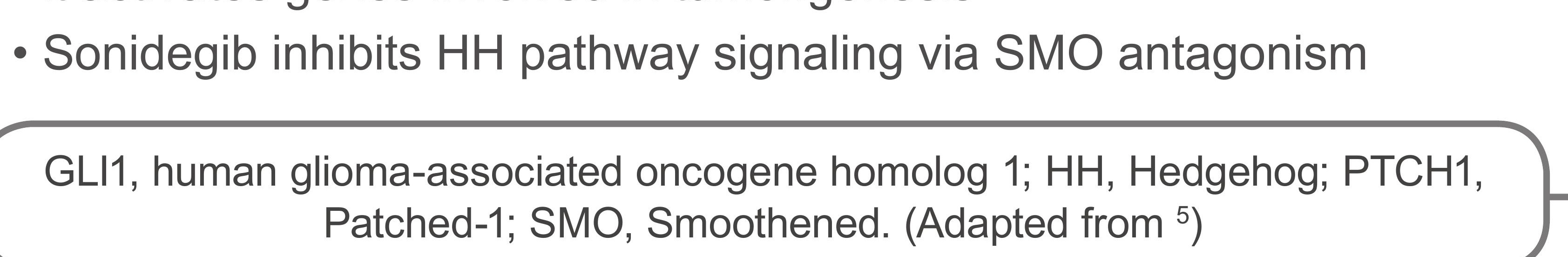

Sonidegib was approved based on results of Outcomes with LDE225 [sonidegib] Treatment trial (NCT01327053) ${ }^{6}$ (Figure 2)

Sonidegib is approved in the US, the European Union, Switzerland, and Australia for the treatment of patients with locally advanced basal cell

In Switzerland and Australia, sonidegib is also $(\mathrm{mBCC})^{6}$

\section{OBJECTIVES}

- Hedgehog pathway inhibitors are a relatively
recent class of drugs

Their long-term safety profile is not yet well

characterized

Safety was one of the key secondary endpoin

(t)

- Adverse events (AEs) monitored at 30 months in

METHODS

BOLT Study Design

BOLT was a randomized, double-blind phase 2

clinical trial conducted in 58 centers across

(countries' (Figure 2)

- Adults enrolled had either histologically confirmed laBCC (not amenable to curative surgery or

radiation) or had $\mathrm{mBCC}$ (where
options had been exhausted)

Patients received either $200 \mathrm{mg}$ or $800 \mathrm{mg}$ of

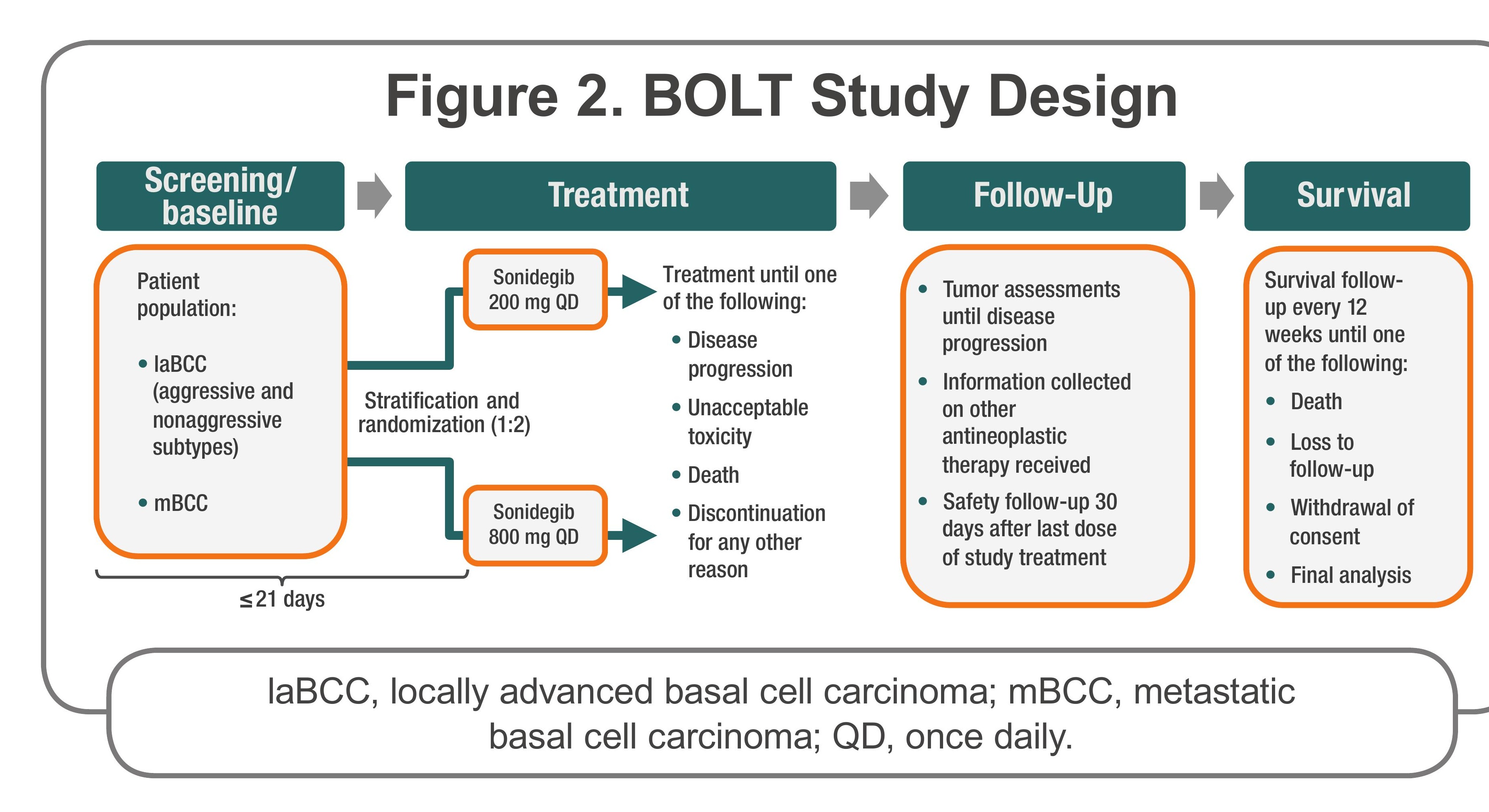

Safety/Monitoring AEs

- Monitoring of AEs was done according to the National Cancer Institute Common Terminology Criteria for Adverse Events version $4.03^{\circ}$

AEs were assessed by central and investigator
review from the first dose until 30 days after the review from the first dose until 30 days after
last dose in patients who received at least one dose of sonidegib

Muscle-related events were also assessed by an independent safety review and adjudication
committee composed of three external experts

\section{RESULTS}

Patient Demographics and Disposition Two-hundred-thirty patients with laBCC $(n=194)$
or $m B C C$ ( $n=36$ ) were enrolled between July 20 , 2011, and January 10, 2013 (Table 1)

Patients were randomized to sonidegib $200 \mathrm{mg}$ $($ laBCC, $\mathrm{n}=66 ; \mathrm{mBCC}, \mathrm{n}=13)$ or $800 \mathrm{mg}(\mathrm{laBCC}$ $\mathrm{n}=128, \mathrm{mBCC}, \mathrm{n}=23)^{\circ}$

Baseline demographics were well balanced

Table 1. Patient Demographics and Disease History

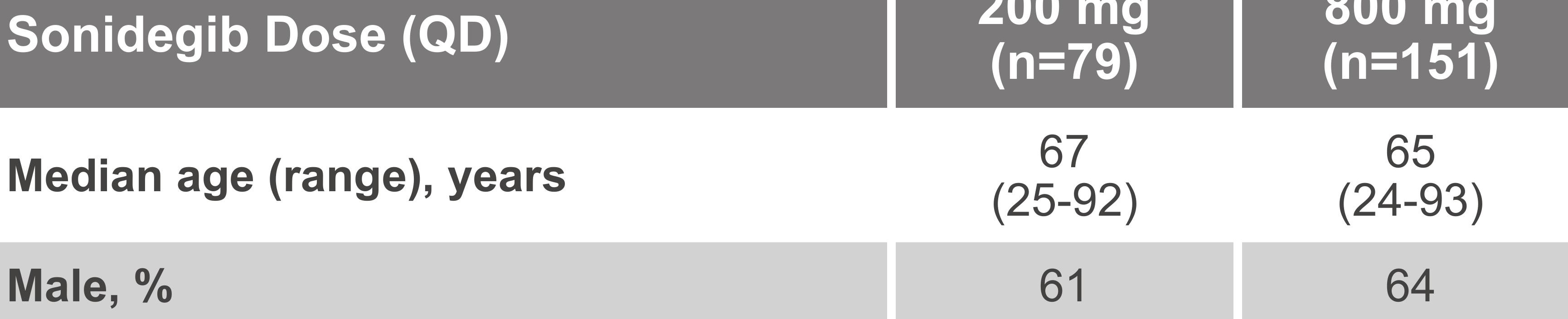

\begin{tabular}{|l|l|l|}
\hline & 61 & 64 \\
\hline
\end{tabular}

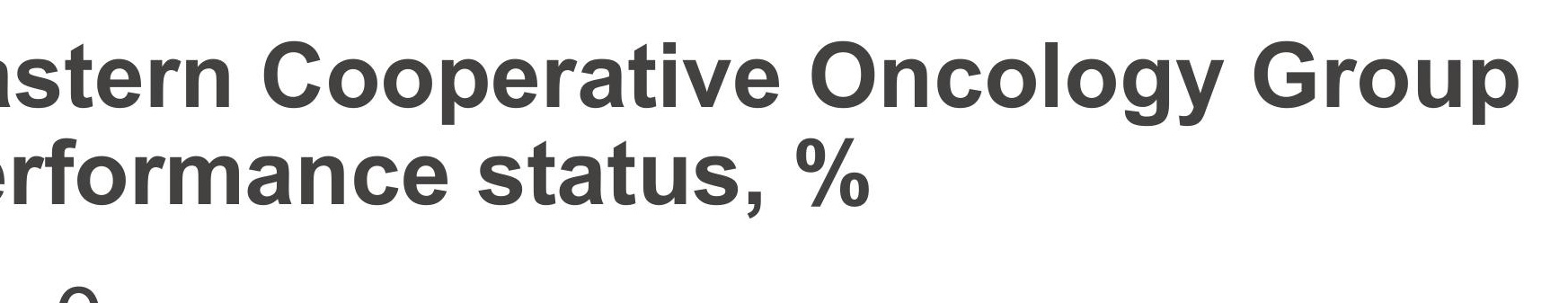

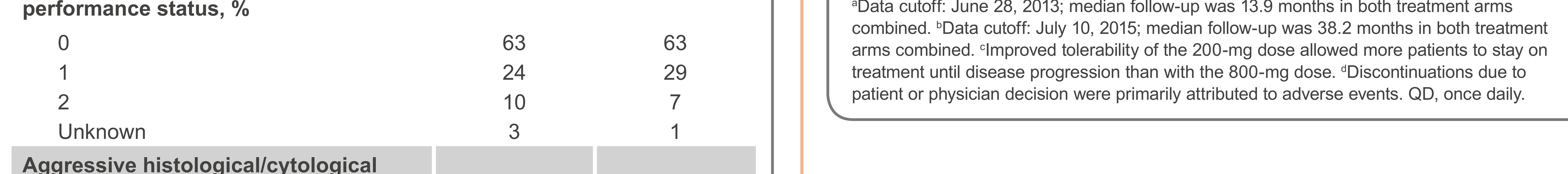

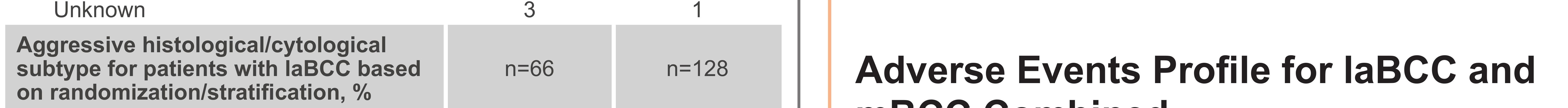

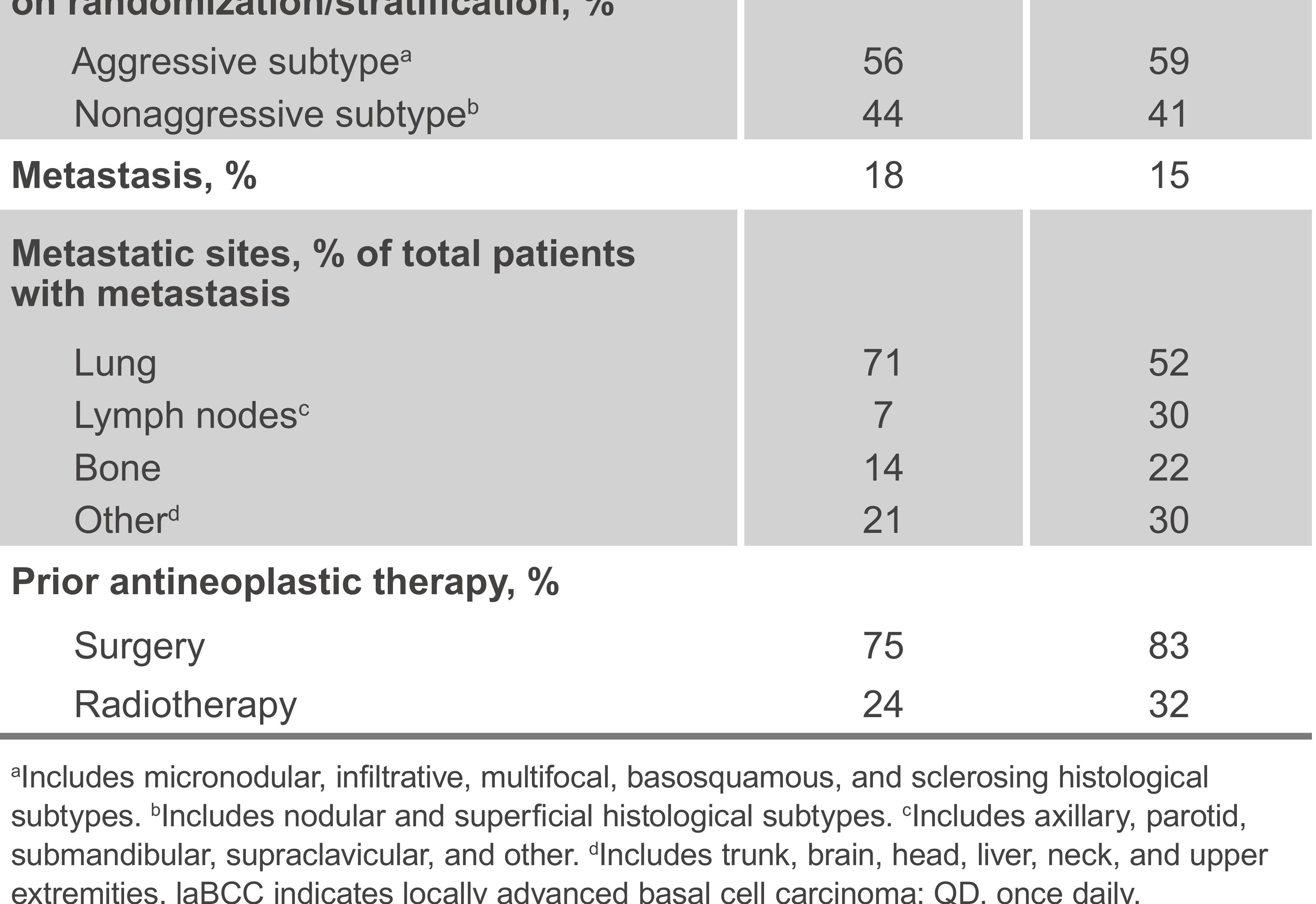

(n) At the time of the 30 -month analysis, $>90 \%$ of
patients in each arm had discontinued treatment (Table 2)

AEs leading to treatment discontinuation in the $200-\mathrm{mg}$ arm occurred in $29 \%$ of patien
compared to $38 \%$ in the $800-\mathrm{mg}$ arm

More patients receiving sonidegib $200 \mathrm{mg} Q \mathrm{QD}$ progression compared fo in the 800-mg QD group ${ }^{9}$

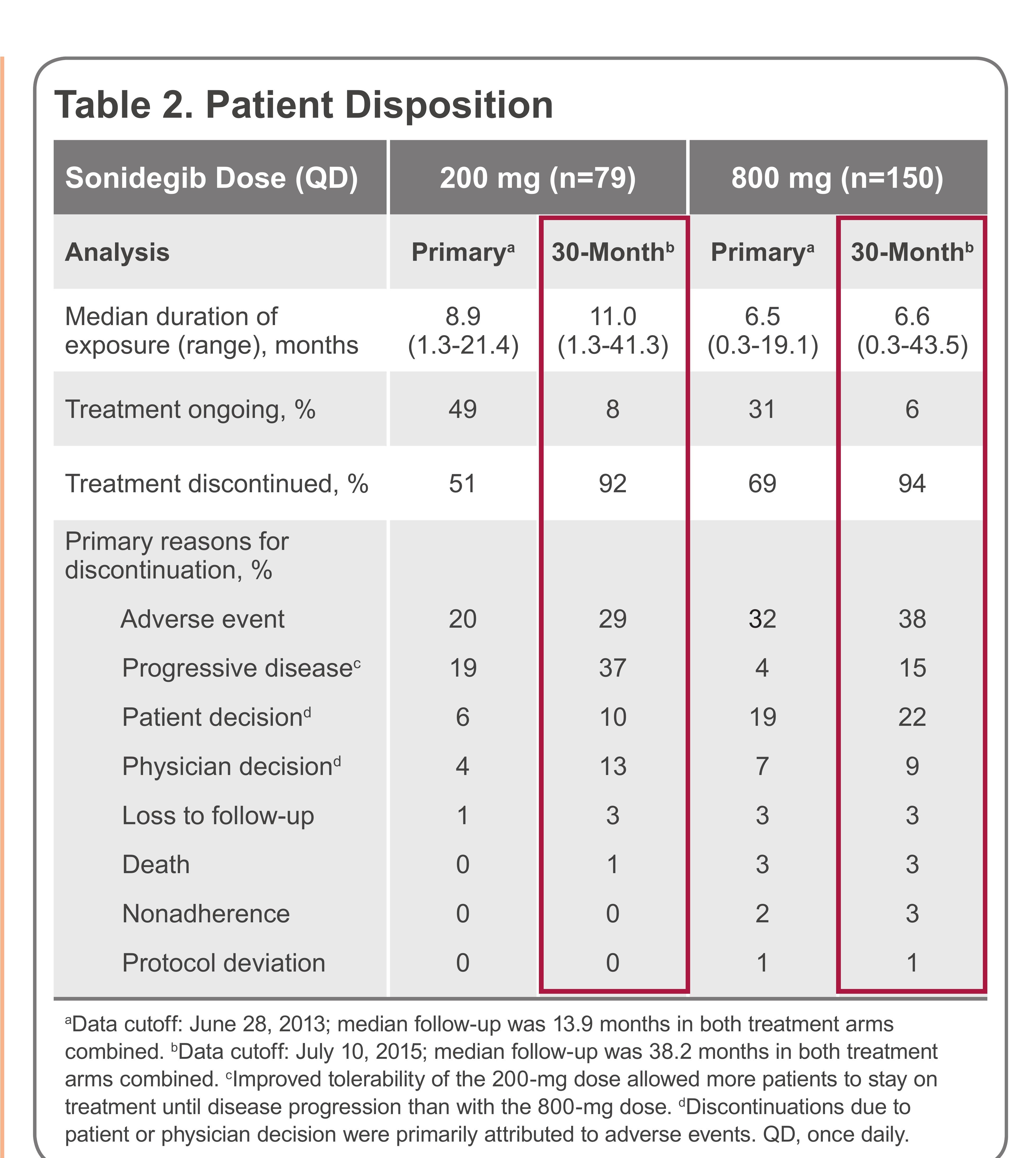

mBCC Combined

At 30 months, the most common (>20\% of
patients) AEs associated with a once-daily

200-mg dose of sonidegib were muscle spasms 12) dys (-2), dysgeusia (44\%;

Few grade 3-4 AEs were reported ${ }^{9}$

- Increased creatine kinase (CK) and

rhabdomyolysis were the most commonly
reported serious AEs among all patients

Because there was no renal impairment, none
of the cases of rhabdomyolysis were confirmed by an independent review and adjudication

- Rhabdomyolysis was defined as CK
concentrations $>10$-fold higher than baseline +

serum from baseline ${ }^{9}$

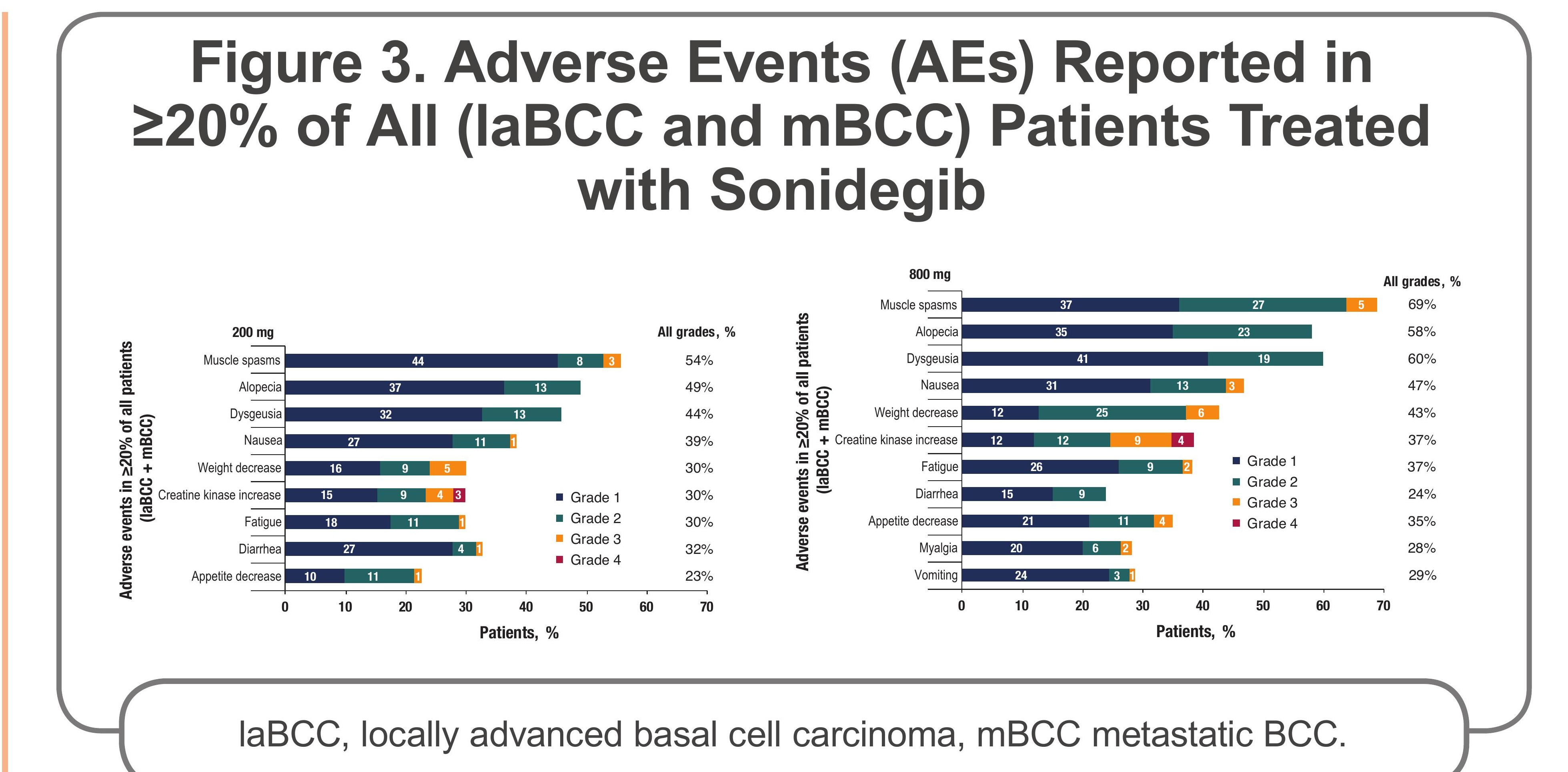

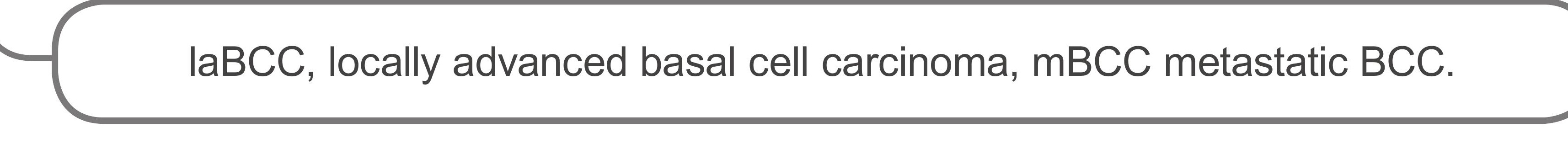
Separated Adverse Events Profile for laBCC

The most common AE for sonidegib at either The most common $\mathrm{AE}$ for $200 \mathrm{mg} \mathrm{QD}$ in $\mathrm{mBCC}$
was diarrhea; for $800 \mathrm{mg} \mathrm{QD}$, it was muscle

spasm $^{9}$ (Figure 5)

Figure 4. Adverse Events (AEs) Reported in $220 \%$
of laBCC Patients Treated with Sonidegib

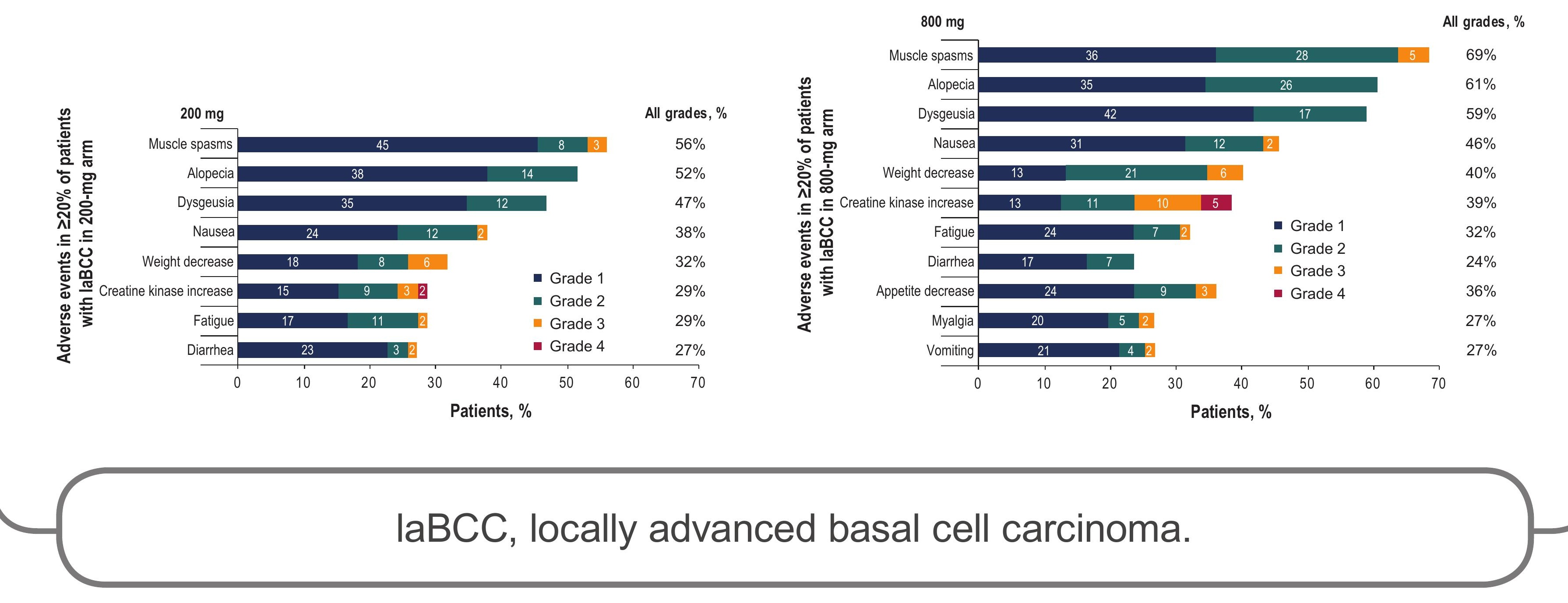

Figure 5. Adverse Events (AEs) Reported in $220 \%$
of mBCC Patients Treated with Sonidegib

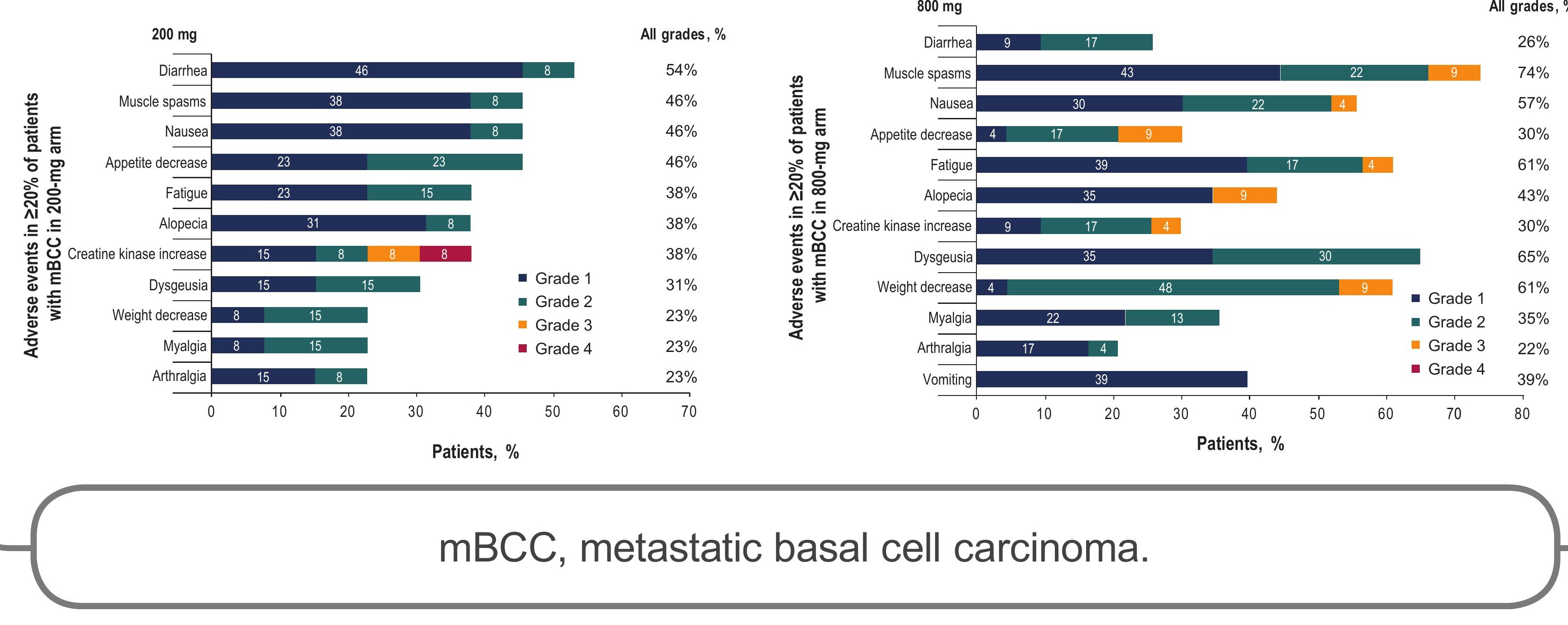

A total of 8 deaths were reported in BOLT, none of which were deemed related to treatment 4 deaths occurred in patients with laBCC, 1 death occurred in the 200-mg arm, and - 4 deachs ocand in pars 4 deaths occurred in patients w
all occurred in the 800-mg arm

\section{CONCLUSIONS}

- At the BOLT 30-month analysis, sonidegib

olerability, with no new safety concerns emerging

in palients with either laBCC or those with $\mathrm{mBCC}$

- Sonidegib $200 \mathrm{mg}$ demonstrated a better beneff-

- These data support the use of sonidegib $200 \mathrm{mg}$

according to local treatment guidelines

REFERENCES

Mohan SV, Chang ALS. Advanced basal cell carcinoma:
epidemiologog and therapeutici innovations. Curr Dermatol Rep.

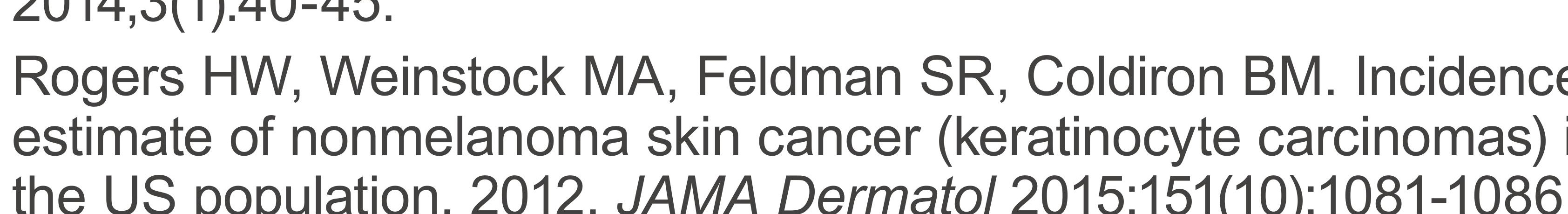

Kish T, Corry L. Sonidegib (Odomzo) for the systemic tratument of

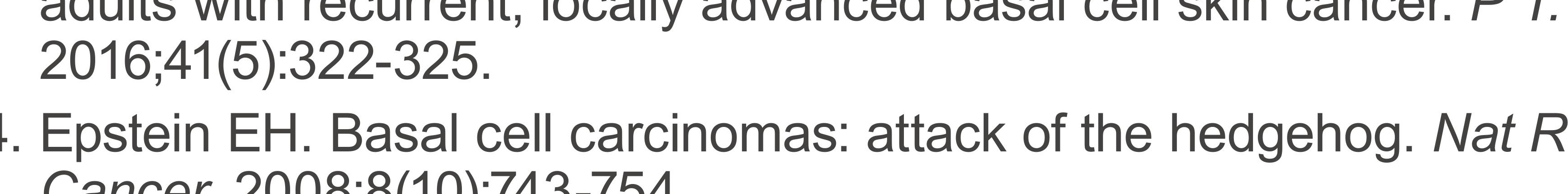

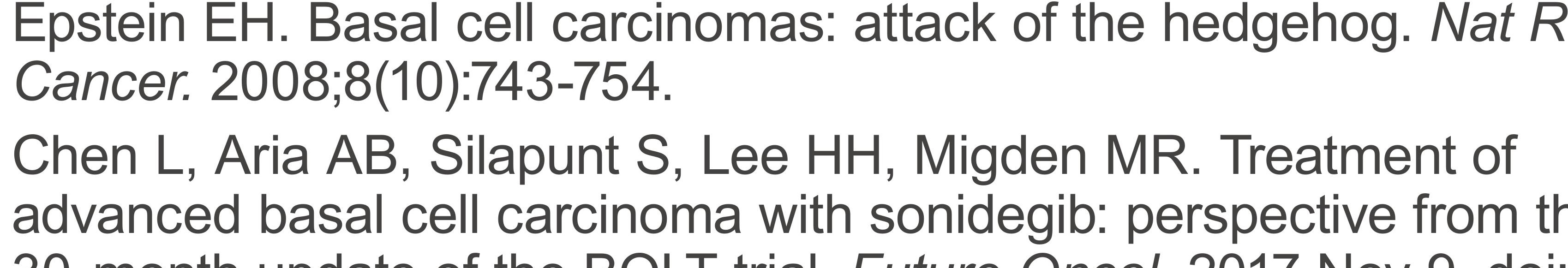

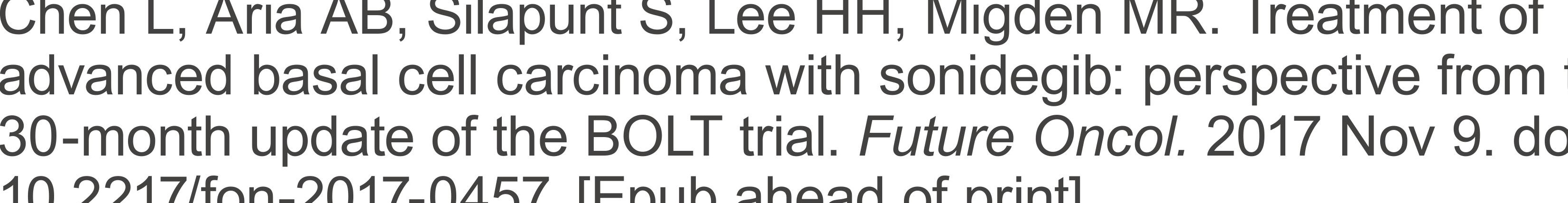

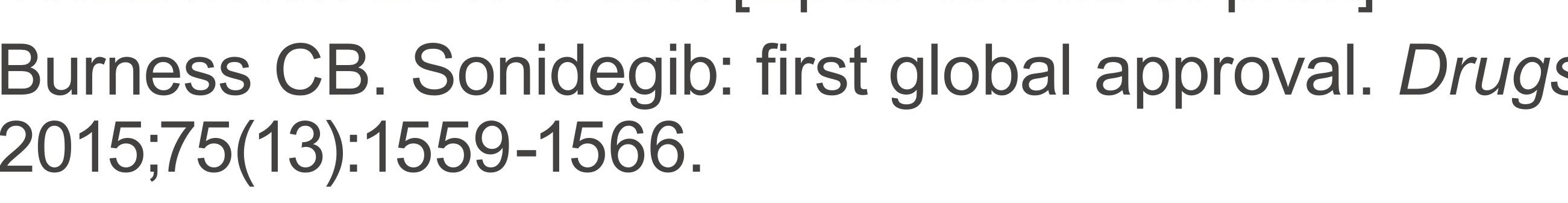

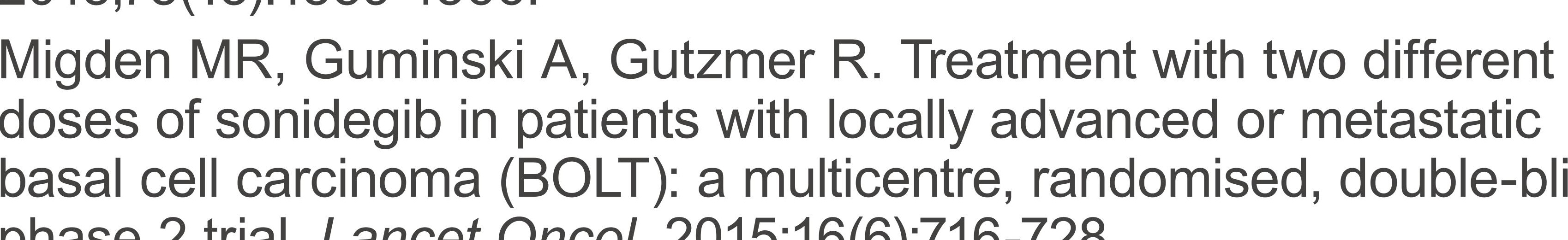

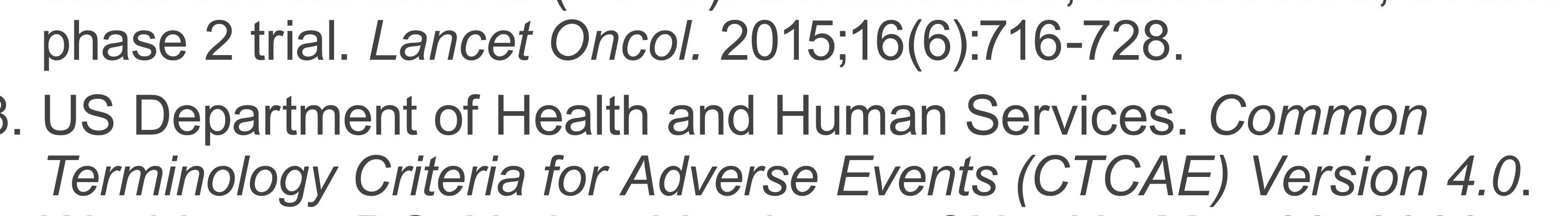

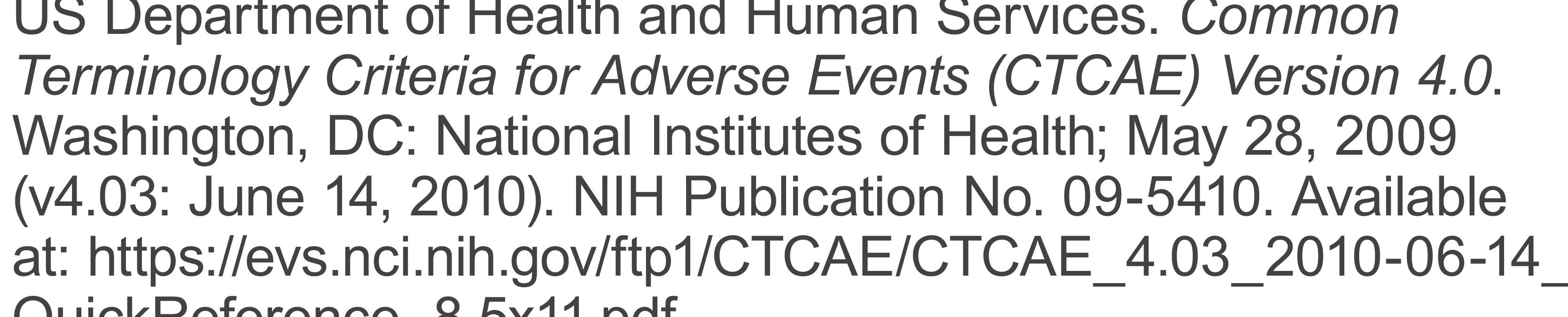

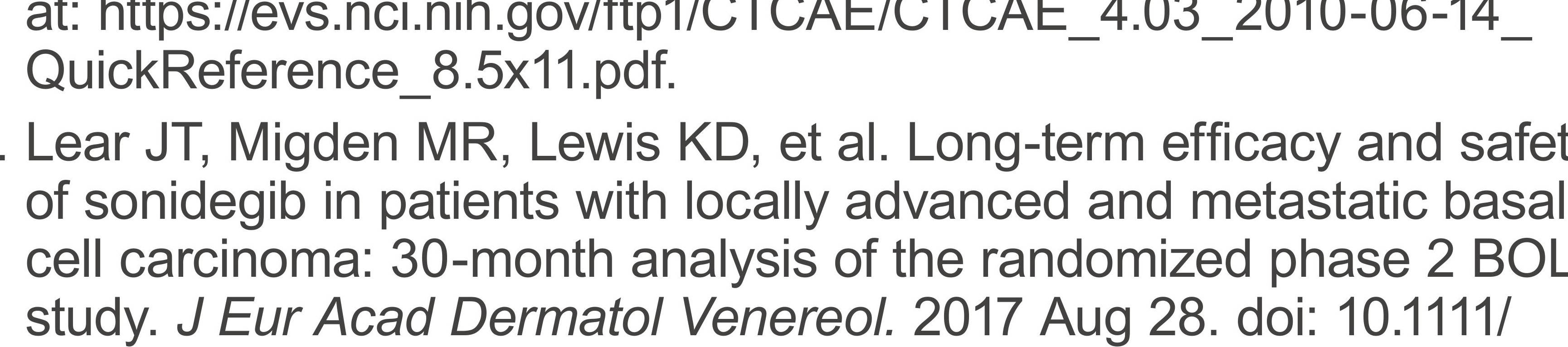

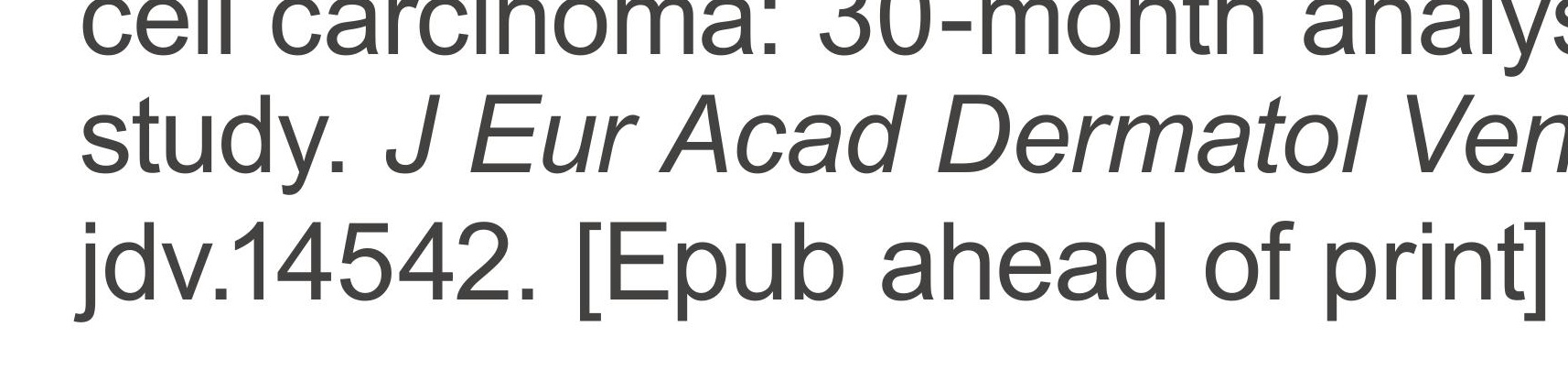

ACKNOWLEDGMENTS

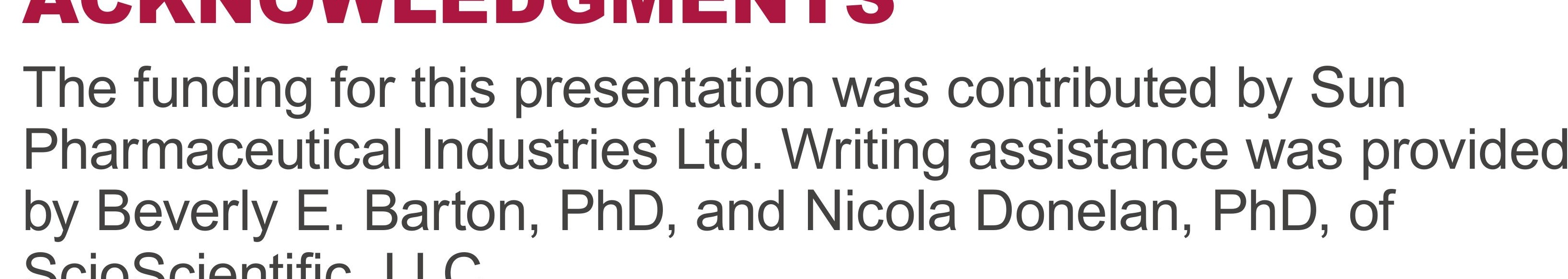

DISCLOSURES

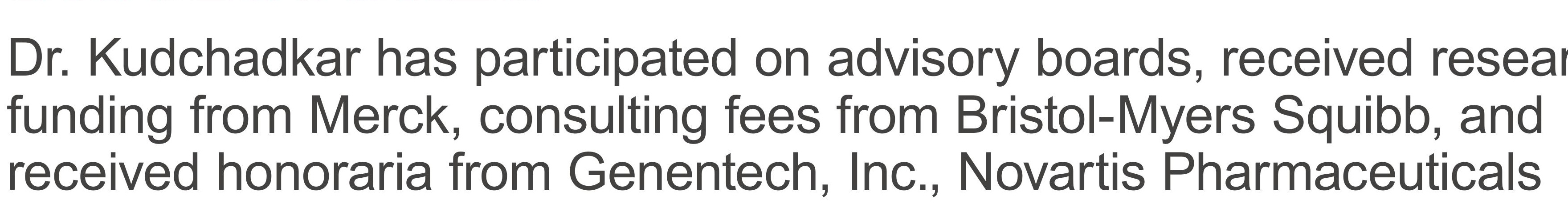

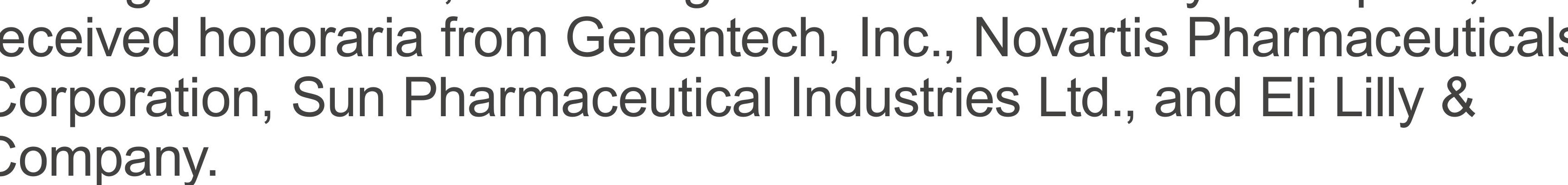

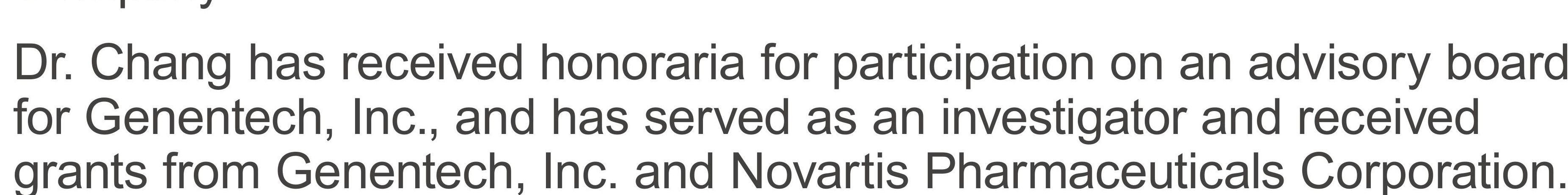

